\title{
Erratum to: Adaptation of the ORTHO-15 test to Polish women and men
}

\author{
Anna Brytek-Matera $\cdot$ Magdalena Krupa $\cdot$ \\ Eleonora Poggiogalle $\cdot$ Lorenzo Maria Donini
}

Published online: 15 April 2014

(C) Springer International Publishing Switzerland 2014

Erratum to: Eat Weight Disord (2014) 19:69-76

DOI 10.1007/s40519-014-0100-0

The affiliation of the corresponding author is missing. The correct affiliation is given below.
A. Brytek-Matera
University of Social Sciences and Humanities,
40-326 Katowice, Poland
e-mail: abrytek-matera@swps.edu.pl

The online version of the original article can be found under doi:10.1007/s40519-014-0100-0.

A. Brytek-Matera ( $\square)$

University of Social Sciences and Humanities,

40-326 Katowice, Poland

e-mail: abrytek-matera@swps.edu.pl

M. Krupa

Polish National Center for Eating Disorders, 60-779 Poznan,

Poland

E. Poggiogalle $\cdot$ L. M. Donini

Sapienza University of Rome, 00185 Rome, Italy 